\title{
La lupa de Daniel Herrera Restrepo: una descripción fenomenológica
}

\author{
The magnifying glass of Daniel Herrera Restrepo: \\ A phenomenological description
}

A lupa de Daniel Herrera Restrepo:
Uma descrição fenomenológica

Fecha de entrega: 22 de julio de 2013

Fecha de evaluación: 15 de noviembre de 2013

Fecha de aprobación: 20 de diciembre de 2013

Juan Cepeda H.*

\section{Resumen}

El artículo nos muestra cómo a partir de las experiencias compartidas con el maestro Daniel Herrera, la fenomenología no dista de ser un trabajo en el cual el filósofo detalla el mundo de la vida como si se tratara de un texto encriptado que exige la reflexión fenomenomenológica, como si este fuera una lupa en manos de un riguroso lector. El texto rememora las visitas del profesor Juan Cepeda a la casa del maestro Daniel Herrera, y cómo éste respondía a sus inquietudes haciendo uso de una lupa para asistir su lectura.

Licenciado en Filosofía y Letras, magister en Filosofía Latinoamericana y doctorando en Filosofía de la Universidad Santo Tomás de Colombia; director del Grupo de Investigación Tlamatinime sobre ontología latinoamericana y líder de Chaski: Red Internacional de Investigadores en Ontología. El presente texto fue presentado al finalizar el seminario doctoral sobre el método fenomenológico, segundo semestre de 2012. Colombia. Correo electrónico: juancepeda@usantotomas.edu.co. 
Palabras clave: Fenomenología, lupa, descripción fenomenológica, mundo de sentido.

\section{Abstract}

This article shows us how from the experiences shared with the Master Daniel Herrera, phenomenology is not far from being a job in which the philosopher details the life-world as if it were an encrypted text that demands the phenomenological reflection, as if it were a magnifying glass in the hands of a rigorous reader. The text recalls the visits of Professor Juan Cepeda to the home of Master Daniel Herrera, and how he would answer his concerns making use of a magnifying glass to assist his reading.

Keywords: Phenomenology; magnifying glass, phenomenological description, a sense of the world

\section{Resumo}

Este artigo apresenta para nós o como a partir das experiências compartilhadas com o Mestre Daniel Herrera, a fenomenología não fica longe de ser um trabalho no qual o filósofo descreve o mundo da vida como se fosse de um texto criptografado que exige a reflexão fenomenomenológica, como se este fosse uma lupa nas mãos de um leitor rigoroso. $\mathrm{O}$ texto relembra as visitas do Professor Juan Cepeda à casa do mestre Daniel Herrera, e como respondeu às suas preocupações, usando uma lupa para auxiliar a leitura.

Palavras-chave: Fenomenologia, lupa, descrição fenomenológica, mundo de sentido. 


\section{Introducción}

Normalmente, los estudiantes olvidamos a los maestros. Al menos eso me han dicho unos pocos maestros a quienes la vida me ha regalado la oportunidad de frecuentar en su enriquecedora madurez. Uno de ellos es de los más grandes filósofos de nuestro país, con reconocimiento más allá de nuestras fronteras, pero con una grave dificultad para ir más allá de los límites de su apartamento, situado en la ciudad de Bogotá, debido a que se está quedando sin el sentido de la visión. Daniel Herrera Restrepo aprendió en los archivos de Husserl, en Lovaina, a vivenciar los fenómenos, para realizar sus descripciones fenomenológicas, y estoy seguro que degustaría observar el paisaje que se atalaya desde el tercer piso en que vive con su esposa, así como seguiría evidenciando, en escritos, cómo la fenomenología continúa marcando el paso en los aprendientes que se acercan a la tradición fenomenológica cuya escuela crece cada día más acá en Colombia. Pero Danielito ya no puede leer, a no ser textos en letra muy grande, y con la ayuda de sus gafas y su lupa. De vez en cuando lo visito, a veces con alguno de mis estudiantes, y siempre nos recibe literalmente con los brazos abiertos y una sonrisa que entusiasma a cualquiera. Es feliz conversando, repasando sus saberes ganados años ha, y compartiendo la alegría de su vida, alegría que tal vez enmudece en sus largos momentos de soledad. En su biblioteca personal, al lado de su computador, nos sentamos al escritorio, en el que siempre hay libros y fotocopias, sus gafas y su lupa. Jamás conversa con ínfulas de sabio, jamás afirma nada con autoridad de académico, jamás se cree un docto de conocimientos con los que podría señalar verdades dogmáticas. Me gusta conversar con Danielito porque sabe escuchar. Tal vez sea un verdadero maestro precisamente porque sabe escuchar y se interesa por uno, y uno se siente bien junto a él... Cuando uno le interroga, busca el dato en su memoria, ofrece una respuesta muy amablemente, y siempre se vuelve hacia su biblioteca, toma el libro exacto que necesita, lo abre, se pone sus gafas y coge con su mano derecha una ya vieja lupa con la que se ayuda. Danielito es muy complejo, para hacer fenomenología de su persona. Su biblioteca es muy rica, como para intentar una descripción fenomenológica de ella. En la última visita que le hice, hace pocos días, me fije en su lupa, y pensé que sería un buen objeto para empezar. Así que solamente me voy a cuidar de su lupa, y nada más. 


\section{Tematización}

Cuando llegamos, Danielito abrió la puerta, extendió sus brazos y alzando la voz nos saludó entusiasmado; después de cruzar algunas palabras, nos hizo seguir a su estudio, nos sentamos, y ahí estaba frente a nosotros Experiencia y juicio, alguna revista, sus gafas y su lupa. Me pregunté si alguno de los visitantes se ha fijado en la lupa de Daniel, y seguramente, en ese momento, me perdí de algún comentario mientras la miraba con detalle.

Tiene un mango de madera, pintado, pero que ya deja ver varios años de uso, aunque esté bien cuidada; el cristal está soportado por un marco redondo de metal, por ahí de unos siete centímetros de diámetro, así que es una lupa mediana por su tamaño y convergencia. El diccionario escolar dice que una lupa es un microscopio simple, de una sola lente convergente. Entre más ancho sea el cristal en el centro, más convergente es, decía mi profesor de física en el colegio. Así que no tiene mayor ciencia describirla, sobre todo porque generalmente siempre hemos visto una, por ahí en cualquier lugar, y se le ha vuelto a dejar sin ofrecerle mayor atención.

Pero esta lupa está sobre el escritorio de Daniel Herrera. Y no es cualquier cosa, entre tantas que tiene nuestro fenomenólogo. Es su lupa. Le acompaña desde hace varios años. No es un simple útil a la mano, hace parte de su mundo de la vida. Ella es tomada en su mano, y le permite a Daniel ver las letras muchísimo más grandes, de tal manera que puede volver a leer. Por la lente convergente, las letras de un viejo libro editado en Hamburgo, en 1948, crecen de tamaño en la medida en que es desplazada por los renglones, y escuchamos cómo lee Danielito. No lee mucho, y vuelve a la conversación. Pero mantiene la lupa en su mano derecha, acompañando los movimientos de su mano. Después de algunos segundos, la vuelve a dejar sobre el escritorio. Ahora veo que el color del mango es un caoba bien oscuro, casi negro pareciera; pero no, no tan negro, pues negro en cambio sí es el soporte del cristal. Ahí está, pues, nuevamente frente a mí, la lupa de Daniel quieta sobre su escritorio.

Cuando, en la conversación, Danielito señala una de sus notas al margen del libro, en letra diminuta, según su costumbre, me pasa Experiencia y juicio, toma su lupa y me la entrega. Ahora tengo la lupa en mi mano derecha, siento su mango que fue torneado no de forma lisa sino con cimas y simas, para asegurar que no la soltemos, seguramente. La acerco a la nota escrita y leo el texto que ahora se me presenta diríamos que en caracteres gigantes, pero que de todas formas no se lee fácilmente 
porque es letra cursiva, $y$, a veces, Danielito ha insertado palabras en otros idiomas, de las varias lenguas que aprendió a hablar viajando por el mundo. Recuerdo ahora si mal no estoy que estuvo en 54 países... Al cristal no le incumbe en qué lengua esté el escrito, este es solamente un vidrio inerte que cumple su función de ampliar la imagen hasta diez veces o más, según confirmo ahora. Observo la lupa, el tacto y finalmente también la dejo sobre el escritorio para atender las explicaciones que nos ofrece Daniel sobre la tematización y la variación.

\section{Variación}

La variación, por lo regular, es imaginaria, en el sentido de que lo que hacemos es presentar varios objetos del mismo tipo al que nos estamos acercando fenomenológicamente buscando comprender lo que todos tienen en común e identificando lo que es meramente accidental. Nuevamente, la lupa se ha movido, porque Danielito lee un aparte del libro Análisis reflexivo: Una primera introducción a la investigación fenomenológica, de Lester Embree. Esta lupa ha permitido aumentar de tamaño el texto que dice:

Es interesante que en esta variación imaginaria del color podemos llegar a reconocer que la silla sigue siendo silla sin importar qué color tiene o por cuál se lo cambia. Por consiguiente, el color es para una silla "inocencia" o "accidental”. Algo no necesita ser marrón para ser una silla. (Embree, 2003, p. 459)

Igualmente, hay lupas con mango de cualquier color, o aparentemente sin color, al que se le ve la madera natural; es más, hay otras lupas cuyo mango no es de madera, sino también de metal, como el soporte del cristal, y no dejan de ser la lupa que son; hasta puede haber una lupa con mango de marfil, u hoy día las encontramos en los puestos de venta callejera con mango de plástico. Precisamente en esos puestos populares vemos la cantidad de tamaños que nos ofrecen: pequeñas, más pequeñas, medianas-pequeñas, medianas-grandes, grandes y muy grandes. El tamaño no es esencial a la lupa.

Gracias a la imaginación y a la memoria se puede variar el objeto acerca del cual realizamos la construcción fenomenológica. Por ejemplo, ahora recuerdo la primera vez que vi la lupa de Daniel. Fue en un salón del edifico de la Biblioteca de la Sede Central de la Universidad Santo Tomás, cuando nos dictaba hace varios años un seminario 
de fenomenología a estudiantes de la Maestría en Filosofía Latinoamericana. Abrió su ejemplar de Crisis, llevó su mano al pecho y de entre el bolsillo interior de su saco extrajo la lupa. Hoy confieso que me impactó ver al maestro leyendo ante sus estudiantes con una lupa, pero, claro, jamás me imaginé que luego, en su apartamento, yo tendría esa misma lupa para leer una de sus notas marginales. No era otra lupa: ni una con mango más rústico o más fino, ni una de otro color, ni una cuyo lente tuviera otra forma, aunque normalmente todas las lupas tienen el cristal redondo. Pero no dejaría de ser lupa si el cristal fuera pentagonal, heptagonal o inclusive cuadrado.

Es más, el cristal no necesariamente debe ser de vidrio. Se le llama cristal, pero este puede estar construido de cualquier material que funcione para ello, y entre más transparente mejor, aunque podría haber lupas amarillentas, verdosas, azulosas, no importa; eso sí, se echa de ver que en todas las lupas hay un cristal, transparente, de aumento, para posibilitar ver más grande el objeto observado cuando este es iluminado externamente.

La lupa nos permite aumentar la imagen recta del objeto que observamos para lo que se necesita la iluminación adecuada. Pero no es necesario romper, cortar o desmoronar el objeto, a diferencia del uso que se da al microscopio: con este instrumento debe usarse una fuente de luz que atraviese la muestra que quiere observarse, por lo que siempre esta se ha de ubicar entre dos cristales muy finos que precisamente permitan el paso de la luz. Obviamente, es bastante diferente una lupa a un microscopio, por más que se construyan lupas binoculares con forma de microscopios.

\section{Ideación}

La descripción fenomenológica nos lleva a apañar la esencia de la cosa observada, pero dejando ya de lado esa cosa en particular. "Es una descripción eidética", dice Danielito. ¿Qué hace que algo sea una lupa y no otra cosa?, ¿cuál es su esencia? Nos referimos entonces a todas las lupas habidas y por haber, inclusive a las imaginadas. Toda lupa debe cumplir con aquello que se nos muestra como su esencia, podríamos decir: su lupeidad. Toda lupa, como la de Daniel Herrera, se constituye por un cristal convergente, que aumenta la imagen virtual que puede observarse de la cosa ante la luz (sea esta la luz natural o una fuente de luz que impacte sobre lo observado). No importa la forma, ni inclusive si el cristal, siendo transparente, tiene alguna coloración. No importa si el cristal tiene un soporte o adolece de él y menos 
importa el material del soporte. Tampoco importa si tiene mango ni la forma o el material de este; a veces, inclusive sobra el mango, por ejemplo, en aquellas lupas binoculares con forma de microscopio. Por ello es que finalmente nos quedamos con que la lupa es un instrumento óptico que ofrece una imagen virtual ampliada del objeto observado, a lo que habrá que añadir que su uso es de corta distancia, ahí cerca al ojo del observador.

\section{Un post scríptum personal}

El mundo de la vida, en efecto, no es un mundo de meros objetos ni de meros procesos objetivos o subjetivos. El mundo de la vida, según esas últimas investigaciones de Husserl, es más bien un mundo de sentido. En mi mundo de la vida no tendría sentido, al menos por ahora, describir una lupa, ni aun siendo la lupa de Daniel Herrera Restrepo. Para mí, tiene sentido, en verdad, la lupa que es Danielito: él es un maestro de cristal, es decir transparente, por el que podemos mirar sin dificultad alguna, de forma muy sencilla (como sucede con la lupa en comparación con el microscopio), ampliada por su experiencia personal (sin quedarse meramente en la lectura que ha hecho de los textos) y convergente en América Latina (aplicando la fenomenología a nuestra realidad, a nuestro mundo de la vida), la imagen virtual de eso que se ve desde la academia tan difícil y tortuoso: la fenomenología.

\section{Referencias}

Embree, L. (2003). Análisis reflexivo: Una primera introducción a la investigación fenomenológica. México: Jitanjáfora. 